\title{
Novel Approaches for Treating Musculoskeletal Diseases: Molecular Orthopedics and Systems Medicine
}

\author{
Kaveh Mashayekhi ${ }^{1,2,3}$, Margaret O’Brien ${ }^{4}$, Florin Zugun-Eloae ${ }^{5}$ and Luminita Labusca ${ }^{*}, 1,6$ \\ ${ }^{I}$ Systems Bioinformatics and Modelling GMBH,39 Basaltstrase D-62540, Tel+4915154924033 Frankfurt, Germany \\ ${ }^{2}$ BioTalentum Ltd, Aulich Lajos str. 26.2100 Gödöllö, Hungary \\ ${ }^{3}$ REMEDI National Centre for Biomedical Engineering Science (NCBES), Orbsen Building, NUI Galway, Ireland \\ ${ }^{4}$ National Centre for Biomedical Engineering Science (NCBES), Orbsen Building, NUI Galway, Ireland \\ ${ }^{5}$ Molecular Genetics and Immunology Department, "Gr. T. Popa" University of Medicine and Pharmacy, Iasi, \\ Romania, Str. Universitatii nr.16 700115 Iasi, Romania \\ ${ }^{6}$ University Hospital Saint Spiridon Iasi Romania ${ }^{\text {st }}$ Independentei Boulevard Iasi, Romania
}

\begin{abstract}
Molecular medicine uses knowledge about cell structure and function for disease, diagnostics, stage characterisation and treatment. The advent of genomic technologies is considerably leading to developments in the field of molecular medicine. The accumulation of detailed information about gene expression, epigenetic variability, protein transcription and functional modulation is contributing to a new era in medicine. Rapid and early diagnostic procedures, molecular characterisation of degenerative and proliferative diseases and personalized therapies are predicted to lead to advancements in health prevention and treatment of disease. Diagnostic tools and therapies based on local and /or general modulation of cellular processes for traumatic or degenerative musculoskeletal conditions are becoming available. A logical consequence of the information derived from extensive data gathering, systems biology and systemic medicine has lead to significant improvements in understanding biological structure and function in a simultaneous bottom top and integrative, holistic manner. The description of disease mechanism at an intimate, subcellular level has a dual benefit. A thorough understanding of the crosstalk involved in molecular pathways both in the normal and the diseased state are expanding scientific knowledge and simultaneously are enabling design cell-targeted and individualized therapies. This paper presents a brief overview of current molecular based treatments available to the orthopedic surgeon and introduces the concept of systemic medicine from the perspective of musculoskeletal pathology.
\end{abstract}

Keywords: Systems biology, systems medicine, molecular biomarkers, gene therapy.

\section{INTRODUCTION}

Orthopedic surgery is a science while it is also a surgical branch treating traumatic, degenerative and tumoral musculoskeletal conditions. Orthopedic conditions do not have an age profile, are difficult to endure and challenging to treat. Trauma or tumors can affect the young or biologically young individuals, while joint, tendon and bone degenerative diseases, are more predominant but not limited to the elderly. Rapid restoration of motion, pain relief, professional and social reintegration is an increasing patient demand and a continous challenge for the surgeon. On the other hand, as non life-threatening diseases, orthopedic conditions are expected to be managed by means of safe comfortable measures, yelding a complete recovery, as is possible. In the continous effort to meeting these demands, orthopedic surgery has always kept pace with latest scientific and technological breakthroughs. After pioneering implantology,

*Address correspondence to this author at the University Hospital Saint Spiridon Iasi Romania $1^{\text {st }}$ Independentei Boulevard Iasi, Romania; Tel: +40749162219;

E-mails: luminitasimion@yahoo.com, luminita.labusca@online.de prosthetics, video and computer assisted surgery, the science of restoring motility employs the use of molecular biology (MB) as the latest resource for advanced care. MB is the science of understanding the molecular basis of living systems [1]. By studying the intimate basis of information storage, transmision and expression, it overlaps with genetics (molecular genetics). Furthermore, MB also includes biochemistry for the study of the structure and function of biologically active substances, in the context of vital processes. Used for decades in orthopedic research, MB is recently making its way to clinical practice [2]. Recombinant proteins for bone and tendon healing, signaling molecules based authologus therapies, gene therapy for tendon and cartilage regeneration, biomarker screening for diagnostic and follow up in osteoporosis and osteoarthritis are some examples of scientific breakthroughs of the last decade, reaching clinical availability. Molecular medicine evolves in two complementary, however distinctive, directions: diagnostics and therapy. This further represents the establishment of the "molecular signature" of a disease as well as the validation of tools for screening the individuals at risk for developing certain condition from a given population. The latter represents generation of controlled 
changes within the living organism, aiming to induce or enhance healing or to block pathogenic mechanisms. Without claiming to be exhaustive, the following is a description of current trends in designing screening diagnostic tools and molecular based therapies for orthopedic conditions. The current status of research and, when applicable, of clinical availability, are briefly outlined in the following paragraphd. In the last part of the article, the reader will be introduced to the concept of systemic medicine in an attempt to identify possible fields of orthopedic surgery in development of the concept.

\section{ASSESSING THE MOLECULAR BASIS OF NORMAL AND DISEASED; MOLECULAR BIOLOGY BASICS}

The "central dogma of molecular biology" [3] states that all information about living structure and function is stored within the cell nucleus as genes, the molecular units of heredity. Genes are composed of stretches of DNA biopolymers of variable length. DNA molecules are doublestranded helices composed of two long polymers of simple units called nucleotides (purine and pyrimidine) -the well known adenine $(A)$, guanine $(G)$ thymine $(T)$ and cytosine (C)-. Genetic information is encoded in the DNA chain as a sequence of nucleotides (scholarly recorded using the letters $\mathrm{G}, \mathrm{A}, \mathrm{T}$, and C). Every cell nucleus contains all the genetic equipment of the respective individual, however, only parts of the genes are "expressed". When expressed the encoded information becomes operational, determining the production of cellular "effectors", the proteins, in an extremely orderly manner. The information coded in expressed genes is "translated" to an mRNA biopolymer with the aid of transcription factors and a "copy enzyme" the RNA polymerase. Different cells within a tissue perform different functions, therefore specific proteins need to be produced, respective to the location within a tissue, specialization and metabolic status. From all genetic equipment of a mature cell, only those genes responsible of the specific protein production will be activated. The genetic code defines how sequences of nucleotide triplets, codons, specify which amino acid will be added during protein synthesis. A three-nucleotide codon in a nucleic acid sequence specifies a single amino acid. By knowing the sequence of a RNA polymer it is possible to predict the structural composition of proteins to be produced by a cell in either normal or pathological states. With the advances of human genome sequencing, the complete set of genetic "instructions" for human cells has been made available [4]. While this remarkable work opened a new era of possibilities in understanding functions and diseases, there is still a lot of research to be done in order to decipher how the identified "words" (sequences) are used by the organism to compose meaningful "sentences" in life processes.

Advanced genomic technologies have made it possible to profile gene and protein expression in normal and diseased structures. Using a bioinformatics approach and advanced multivariate bio-statistical methods, disease and/or tissue related individualities can be identified. Therefore it is possible at a molecular level to assess the "signature profile" of a metabolic condition or a disease, enabling the design of detection and follow up tools, the molecular biomarkers. Biomarkers are generally defined as parameters which can be objectively measured as indicators of a physiological or pathological process within a living system [5]. They can be anatomical, physiological, biochemical, or molecular characteristics which have been associated with a normal or diseased status in a certain organism. Accordingly to their nature, biomarkers can be measured in various ways (laboratory tests, imaging, physical examination) and can also be utilized to assess the response to therapeutically interventions. Genomic technologies and bioinformatics processing of data are enabling rapid advancement in the field of molecular biomarkers. Combination of "omics" (genomics, transcriptomics, proteomics, metabolomics), with information contained in multicentric electronic medical record (EMR) systems and with extensive genomic wide association studies (GWAS), are fuelling the biomarker discovery research. This approach is required to deliver easy to use diagnostic and follow up biomarker panels. Several few milliliters of bodily fluids can be used for detection of molecules of interest that are characteristics for diagnostic and prognostic tools or prediction of a disease. Validation of molecular biomarkers raises new possibilities for drug discovery offering valuable tools for assessing pharmacological intervention and facilitating drug development and approval [6]. Deciphering the molecular profile of a disease suggests the possibility of designing therapeutically interventions at cellular and/or DNA level (including genetic and cellular therapies). Other applications such as engineering recombinant produced proteins and hormones, the production of synthetic organic polymers, nanoparticles as carriers or drug delivery systems, are close to being used in clinical settings.

\section{BIOMARKERS FOR MUSCULOSKELETAL DISEASES}

Osteoarthritis (OA) and inflammatory arthritis (rheumatoid arthritis $R A$, psoriasic arthritis, $P A$ ) are the leading causes of pain and chronic physical disability worldwide, having a enormous impact on the quality of life, in the context of an ageing population [7]. Originating from the field of cancer research, biomarker discovery science is regarded as having an increasing importance for the management of joint degenerative diseases. The goal is to deliver non invasive, non costly, easy to use tools for the detection of pre symptomatic joint pathology. To date, detection of articular cartilage destruction relies mainly on radiographic criteria. Decreases in joint space width (JSW) on plain X-Ray, the "gold standard" radiological evidence for cartilage pathology, is seen only after significant degradation has occurred. To date, the only proven successful treatment for symptomatic joint is prosthetic replacement, a reconstructive procedure indicated for advanced stages of cartilage damage, especially in the elderly. Long years of pain and disability are the prospect for the younger subjects with arthritic joints. Available treatments addressing symptoms or attempting to influence cartilage metabolism are, too often, of limited efficiency, have excessively high costs and non-negligible side effects. Molecular profiling for the early stages of cartilage damage from the perspective of biomarker discovery science is perceived to be the new approach in the field of cartilage degeneration pathology. Not only can preclinical stages of the disease be detected, but efficient molecular therapies could emerge, leading to the design of stage oriented therapeutic algorithms. Aiming to concentrate resources and 
worldwide interest in the field, OARSI (Osteoarthritis Research International Society) has launched in 2008 the "Global OA biomarker initiative [8]. Workshops and meetings organized with partners such as AOOSM (the (American Orthopedic Society for Sports Medicine) and the ORS (Orthopedic Research Society and co founded by NIAMS (US National Institute of Arthritis Musculoskeletal and Skin Diseases are held on a yearly basis. In this context, the need for biochemical biomarkers at the pre-radiographic OA state has been identified as enabling the design of disease-modifying therapies. Potential molecular targets for OA therapies and for defining families at risk for the disease are identified and made available [9]. A review of the biomarkers papers published in 2012 under the OARSI "year in review series" offers a comprehensive summary of the progress in the field [6]. Even though there is, to date, no accepted classification, joint degradation potential molecular biomarkers can be grouped together based on their biological function and/or tissue of origin. In a large patient cohort study of early knee and hip OA, potential biomarkers have been clustered into groups concerned with bone and cartilage degradation, synovial tissue, inflammation and cartilage synthesis [10]. Several classes of molecules are being studied for their use as potential OA biomarkers. Polypeptide chains originating from collagen degradation such as the urinary C-terminal telopeptide I or II (uCTX-I, uCTXII) have been identified as being increased in patients with rapid destructive hip OA [11] and hemophilic joint degradation [12]. Serum cartilage oligomeric protein (COMP), a matrix protein, is regarded as a potential marker of OA severity [13] or a marker of increased synovial activity associated with OA [10]. Glycoproteins that become incorporated into cartilage fibrillar ECM, for example fibulines, have been demonstrated to be increased in the serum of OA patients [17]. Another group of glycoproteins, secreted FSTL-1 (Follstatin like proteins) produced by the synovium, considered to be RA auto antigens, are now being examined as potential diagnostic and predictive biomarkers for $\mathrm{OA}$ [18]. Cytokines, proteins secreted by cells of the immune system for cell-cell signaling purposes, exist in local inflammatory sites at very low concentrations that can increase by thousand-folds in response to pathogenic processes. Different cytokines, usually used in a panel of 4 12 combinations, have been regarded as suitable biomarkers for joint inflammation, associated with osteoarthritis (OA) [14] or with the inflammatory rheumatisms RA or PA [15]. Serum IL-15 (sIL-15) could serve as a useful biomarker of disease severity in patients with early OA [16].

An interesting group of cytokines, adipokines, involved in regulation of insulin sensitivity and adipose tissue metabolism, have been recently correlated with the presence of cartilage degradation markers. Increased adiponectin [20] and omentin-1[21] levels in synovial fluid or serum of OA patients are recommending them as potential early stage OA biomarkers. Leptin, a key regulator of energy expenditure, fat metabolism, growth processes and intra-uterine development has been correlated in vitro with chondrocyte differentiation. In a populational study, leptin and leptin receptors have been found to be increased in the serum of obese patients suggesting a link between obesity and joint integrity [22].
Classically identified as being involved in immune defensive mechanisms, complement system activation associated with inflammatory rheumatisms and chondrotoxicity is proven to contribute to with both OA and RA pathogenesis [19]. Membrane attack proteins, MAC, the final results of complement system activation, were colocalized with matrix degradation enzymes (MMP- 13) around cultured human OA chondrocytes.

Increasing numbers of studies are identifying various types of molecules of different roles and structures, candidates as potential biomarkers for joint degradation. They are, to date, dozens of clinical trials testing different combinations of cytokines for the early assessment of degenerative or inflammatory joint conditions [23].

\section{MOLECULAR THERAPIES FOR MUSCULOSKELE- TAL DISEASES; ENGINEERED PROTEINS}

In the $1960 \mathrm{~s}$, an orthopedic surgeon with a passion for biochemistry [24] identified the existence of a soluble bone matrix glycoprotein which can induce the differentiation of osteo-progenitor cells into mature osteocytes. The molecule named bone morphogenetic protein (BMP) was the first of the large family of growth factors to be discovered, proteins capable of stimulating cell growth and differentiation. However, production and large scale clinical use of BMP became possible only recently by means of recombinant technologies [23]. cDNA encoding the protein of interest can be inserted by means of an expression plasmid within the genome of a host cell which will begin producing the transferred gene. The first large success of the technique was in the production of insulin. Recombinant insulin is synthesized by inserting the human insulin gene into cultured bacteria, E. coli. Following the isolation and expression of BMP cDNA, two recombinant human proteins - rhBMP-2 and rhBMP-7 (OP-1) - are now commercially available for the treatment of delayed unions, non unions and spine fusions [25].

Protein structure modification is another method for enhancing a desired property of a naturally existing molecule. Etanecerpt is an engineered molecule containing two TNF- $\alpha$ receptors produced by recombinant DNA technology in a mammalian cell line expression system [26], which is clinically available for the treatment of inflammatory arthritis.

Monoclonal antibodies (Mab) are a rapidly increasing field of engineered molecules for use as diagnostic tools and in medical treatments. In living organisms an antibody, usually an immunoglobulin protein, is produced by the B cells of the immune system, for defensive purposes. The antibody will bind to a specific target of the given molecule, called an antigen. Monoclonal antibodies are produced by a cell line which is a clone of a single B cell. It is possible to obtain antibodies to basically every substance aiming its detection, purification or targeted therapeutical intervention. Human monoclonal antibodies are produced industrially by murine cell lines and used as diagnostic tools (combined with a fluorescent molecule in immunohistochemistry or flow cytometry) or therapies. Monoclonal antibodies used for anti-inflammatory purposes (mainly anti TNF- $\alpha$ ) are now utilized in established treatments that are approved for several autoimmune diseases (see Table 1). 
Table 1. Monoclonal Antibodies Approved for Therapeutic Use

\begin{tabular}{|c|c|c|c|c|c|c|}
\hline Generic Name & $\begin{array}{l}\text { Trade } \\
\text { Name }\end{array}$ & $\begin{array}{l}\text { Antibody } \\
\text { Format }\end{array}$ & Antigen & $\begin{array}{l}\text { Approved } \\
\text { Indication }\end{array}$ & FDA Approval & EMEA Approval \\
\hline Infliximab & Remicade & Chimeric, IgG1 & $\mathrm{TNF} \alpha$ & $\begin{array}{l}\text { Crohn's disease and } \\
\text { rheumatoid arthritis }\end{array}$ & $98 / 08 / 24$ & $99 / 08 / 13$ \\
\hline Etanercept $t^{1}$ & Enbrel & huFc $\gamma 1 / \mathrm{TNFr}$ & TNF $\alpha$ and $\beta$ & $\begin{array}{l}\text { Autoimmune } \\
\text { diseases such as } \\
\text { ankylosing } \\
\text { spondylitis }\end{array}$ & $98 / 11 / 02$ & $00 / 02 / 03$ \\
\hline Adalimumab $^{2}$ & Trudexa & $\begin{array}{l}\text { Human, IgG1 } \\
\text { (PD) }\end{array}$ & $\mathrm{TNF} \alpha$ & $\begin{array}{l}\text { Crohn's disease and } \\
\text { rheumatoid arthritis }\end{array}$ & $02 / 12 / 31$ & $3 / 9 / 2001$ \\
\hline Alefacept ${ }^{1}$ & Amevive & huFc $1 /$ LFA-3 & $\mathrm{CD} 2$ & $\begin{array}{l}\text { Chronic plaque } \\
\text { psoriasis }\end{array}$ & $3 / 1 / 1930$ & NA \\
\hline Natalizumab $^{3}$ & Tysabri & Humanized, IgG4 & Integrin- $\alpha 4$ & Multiple sclerosis & $04 / 11 / 23$ & $6 / 6 / 2027$ \\
\hline Golimumab & Simponi & Human IgG & $\mathrm{TNF} \alpha$ & $\begin{array}{l}\text { Rheumatoid arthritis, } \\
\text { psoriasic arthritis }\end{array}$ & $24 / 04 / 09$ & $20 / 10 / 09$ \\
\hline $\begin{array}{c}\text { Tocilizumab } \\
\text { Ustekinumab } \\
\text { Certolizumab pegol } \\
\text { Belimumab }\end{array}$ & $\begin{array}{l}\text { Actemra/ } \\
\text { Roactemra } \\
\text { Stelara } \\
\text { Cimzia } \\
\text { Benlysta }\end{array}$ & $\begin{array}{l}\text { Humanized IgG1 } \\
\text { Human IgG1 } \\
\text { Humanized } \\
\text { Human }\end{array}$ & $\begin{array}{c}\text { Anti IL-6R } \\
\text { antiIL-12 and IL-23 } \\
\text { anti TNF } \alpha \\
\text { B cell activating } \\
\text { factor }\end{array}$ & $\begin{array}{l}\text { Rheumatoid arthritis, } \\
\text { juvenile arthritis } \\
\text { Psoriasis, Psoriasic } \\
\text { arthritis, Multiple } \\
\text { sclerosis } \\
\text { Chrohn disease } \\
\text { Rheumatoid arthritis } \\
\text { Systemic Lupus }\end{array}$ & $\begin{array}{c}11 / 01 / 11 \\
25 / 11 / 2009 \\
22 / 04 / 2008 \text { for Chrohn } \\
29 / 03 / 11\end{array}$ & $\begin{array}{c}01 / 10 \\
20 / 11 / 08 \\
26 / 06 / 2009 \text { for RA } \\
06 / 11\end{array}$ \\
\hline
\end{tabular}

Excerpted and updated from Chames, P, [27] with permission, copyright Journal compilation (C) 2009 The British Pharmacological Society"

${ }^{1}$ These molecules are fusions between the IgG1 Fc portion and a receptor. On 2 May 2008, the FDA placed a black box warning on Etanercept due to a number of serious infections associated with the drug.

${ }^{2}$ Adalimumab is commercialized under the trade name Humira in USA.

${ }^{3}$ Natalizumab was voluntarily withdrawn from the market in February 2005. On 5 June 2006, FDA approved a special restricted distribution program.

\section{GENE THERAPY IN ORTHOPEDICS}

Gene therapy relies on DNA as a therapeutic agent, in order to supplement or to suppress the function of certain genes in living cells. DNA encoding the therapeutic gene can be used in order to replace a mutated gene (most common for Mendelian diseases involving the mutation of a single gene) or a protein drug (rather than a natural human gene) to provide the desired effect within a cell function. The DNA strand containing a gene sequence, in this case for therapeutic purpose, is referred to as a "transgene" Delivery of transgenes within a cell genome requires a "vector". The carrier can be a virus (retrovirus, adenovirus, lentivirus) or a non viral method (injection of naked DNA, electroporation, the gene gun, sonoporation) [28]. Musculoskeletal tissue restoration and the treatment of OA are the domains in which extensive efforts in establishing gene based therapies are currently being employed. Bone, cartilage, ligament or intervertebral disc regeneration by delivery of transgenes encoding growth factors is an appealing strategy as it could waive the inconvenience of their rapid clearance from the body, could make use of already existent technologies and could complement already existent therapeutic procedures. Several gene transfer methodologies are performed either by means of autologus, cultivated cells (ex vivo gene delivery), using a gene activated matrix (GAM) or processing the respective autologus tissue within a single procedure (harvesting, transduction and re-implanting), the "expedited ex vivo gene therapy" [29]. Gene transfer for musculoskeletal tissue repair or regeneration has proven successful in animal models and is currently the object of several clinical studies. Despite the promising results derived from preclinical models, translation to the clinic is rather tedious. Factors contributing to the slow advancement of the procedure primarily involve concerns regarding gene therapy safety, especially regarding the use of viral vectors. Costs involved in the set-up of clinical trials and the disputed risk: benefit ratio in a category of non life threatening diseases, are factors still impeding gene therapy access to clinical practice. Using transgenes, articular and periarticular tissues can be engineered to produce anti-arthritic factors and by doing so to provide a sustained, local therapy for OA joints Local delivery of genes within joints (rabbit synovial cell transfected with human interleukin 1-receptor- antagonist protein; IRAP or IL-lra) was reported as early as the beginning of the 1990s [30]. An in vivo gene therapy study reported the delivery of equine IL-IRa gene for the treatment of experimental equine OA. Elevated intra-articular expression of interleukin-1 receptor antagonist induced a significant improvement of pain and disease activity as well as the preservation of articular cartilage [31]. Different genes and vectors have been used to treat OA or inflammatory arthritis. A first gene therapy application in human used a retrovirus (MFG-IRAP) to introduce human interleukin-1 antagonist (IL-1Ra) cDNA within metacarpophalangeal joints of RA patients [32] The procedure, targeting the IL-1 molecule, a major mediator of pain, inflammation and cartilage degradation in arthritic joints, is used in clinical trials in safety and efficiency phases. Ex vivo transfer of transforming growth factor- $\beta 1$ (TGF- $\beta 1$ ), an enhancer of cartilage metabolism, uses an established line of genetically modified human chondrocytes as allogeneic donors for gene delivery [33]. Recombinant AAV2 is used in clinical trials for in vivo, local delivery of etanecerpt transgene 
((tgAAC94, molecule already in use for inflammatory arthritis therapy as a systemic anti TNF- $\alpha$ therapy) [34]. Intra-articular administration of the cDNA can decrease the frequency of administration and the possibility of extraarticular adverse side effects, as well as reduce costs [28]. Conversely, the strategy of systemic gene therapy is designed accounting for general effects in systemic inflammatory diseases. The transgene can be delivered to a specific site (such as the skeletal muscle) from where the desired molecule will be released within the circulation over an extended period of time. Good results have been demonstrated in animal models [35] however the translation to human application still needs refinement of the long term systemic delivery of anti-inflammatory proteins, due to the potential risk of interfering with the immune response. Facilitated local therapy for OA makes use of the ability of immune cells to homing within inflammation sites. Genetic modification of antigen presenting cells to realize therapeutic immunomodulation after homing in affected joints is perceived to be a promising approach. The transgenes IL-4, IL-10, indoleamine 2, and 3-dioxygenase have proven to be efficient in murine models of OA, suggesting a potential for their use in future human applications [35]. Intervertebral disc degeneration (IDD) can be prevented or even reversed using gene transfer. Growth factors transgenes which enhance extracellular matrix production as well as inhibitors of ECM breakdown can be injected directly intra-discally to arrest the progression of the disease and alleviate symptoms. Human disc explants or animal model studies have proven efficiency of ILR1-a to stop ECM breakdown [36]. Recombinant growth factors BMP-2, TGF- $\beta 1$ or IGF- 1 have been demonstrated to increase proteoglycan synthesis in human disc cell cultures [37]. Various clinical trials using rhGDF-5 injected intradiscally into subjects with degenerative disc disease are ongoing [38]. Targeting the phagocytes activated by wear particles and responsive of prosthetic aseptic loosening is an interesting application of gene therapy. cDNA transfer can be used to obtain production of factors decreasing phagocyte release or counteracting the effect of the released mediators. In a mouse calvarial model, osteoprotegerin cDNA, efficiently inhibited osteoclastogenesis and osteolysis [39]. In an in vitro study, interface cells were transduced with HAdV-5 vector carrying the $E$. coli-derived nitroreductase gene sensitized to the prodrug CB1954 [40]. The same group proposed a methodology of aseptic loosening management by removing the sclerotic interface tissue surrounding a loose implant, using the previously mentioned gene-directed enzyme pro-drug therapy, followed by cement filling of the gap surrounding the implant, this being the subject of a clinical trial [41].

Preclinical trials use the osteoprotegerin transgene for systemic osteoporosis treatment [42] and IL-12, IL-18, IL-13 or p53 and osteoblastoma gene for osteosarcoma treatment [43] testifying to the diversity gene therapy applications in musculoskeletal diseases. With all the technological advancements, diversity of approaches and plethora of available scientific evidence, to date there is no gene therapy product yet available for the orthopedic surgeon. The recent breakthrough of Glybera, the first gene based product approved in Europe [44] may have lead to a new era of opportunities, at least from regulatory perspective, accounting for a step advancement of gene based musculoskeletal treatments.

A review of on-going clinical trials, as well a comprehensive evaluation of the constraints gene therapy faces while translating to clinics, is available for further reading [45].

There are many advances in which molecular medicine successfully improves every-day orthopedic practice. Streamlined by cutting edge genomic technologies, the relatively new approach of biomarker discovery is set to generate advanced diagnostic methods and therapeutic targets. Small molecules and molecular engineering, gene technology and gene therapy, may soon be used in clinical practice. However, one particular aspect emerging from the mere use of advanced technology has to be taken into account. The amount of descriptive information which accumulates on a daily basis as result of hypothesis-driven experiments, particularly from the use of omics technologies overcomes human brain processing capabilities. Advanced statistical and bioinformatics techniques are needed to make sense of the large volume of data that is generated. Specific methodologies derived from advanced mathematics and information technology are introducing the digital era in biology. A shift in paradigm is required for an integrative approach for placing the data in the context of their biological meaning. Thus, systems biology advancements may lead to improvements in musculoskeletal therapies, regenerative medicine and stem cell therapies. The importance of experimental and systems biological approaches for achieving a better understanding of stem cell behaviour and properties has been regarded as the next important step in the translation of stem cell based therapies towards clinical application.

Life processes can now be perceived in detail, at a molecular level, in quantities and degrees of complexity, which were never deemed possible previously. The use of advanced mathematics for the manipulation of large quantities of information unveils complicated biological networks, predicts interrelations and interconnectivity, thus introducing systemic thinking in biology and medicine.

\section{STEPPING FORWARD; SYSTEMS MEDICINE, THE CURRENT CONCEPT}

The development of systems biology has been attributed to the increasing quantity and availability of ultrastructural biological data. Making use of the information gathered by means of omics" technologies" requires an integration of experimental and computational research, therefore enabling a systemic perspective for the description of biological phenomena [46]. However, systems medicine is not the mere translation of the terminology from computer and life sciences to the medical field. From the systemic thinking perspective, a human being is a complex system with structural multiplicity and multilevel hierarchies organized as a scale-free network. It functions as an open informational system characterized by robustness, self organization, adaptability and connectivity. Digital biological information, genome encoded or epigenetic, is integrated and transferred in biological networks. Information is coded hierarchically in DNA, RNA, proteins, differentiated cells, tissues, organs, organisms, and the environment. The system is characterized 
by multilevel interactions within networks with interdependent connectivity. The environment affects every level of the hierarchy and creates several interfaces of communication with the system, adding to the variability and challenging adaptability in a time- and individual- sensitive manner.

Health (defined as physical, psychological, emotional and social wellbeing and not the mere absence of disease or disability) is the harmonious functioning of the human system. Any perturbation of structure, network and connectivity potential which overcomes self regulatory capabilities of the system, generates impaired states of functioning and disease.

In this respect, therapeutical intervention can be perceived as an attempt to readjust the system structure, functioning and/or connectivity. Maximum efficiency and persistence of results can be expected with this approach. Systems medicine takes into account human individuality, complexity of different level pathological mechanisms and variability in response to external interventions. Denominated "P4 medicine" (Preventive, Predictive, Participative and Personalized) [47] is expected to represent a significant upgrade in health care. It has been stated that systems biology applied to medicine has potential consequences in clinical trial design, re-definition of clinical phenotypes and disease predisposition based on molecular parameters, discovery of effective biomarkers to be used for risk assesment, diagnosis and prognosis, implementation of combinatorial therapies, improvement of drug efficency, safety, delivery, timing and dosage of therapy [48].

Complex aspects involved in the design of preventive and predictive measures for health maintenance have to be considered. Therapies are to be rethought in the context of systemic functionality and personalized effect. All this has the potential of introducing radical changes in medical practice in the proximate future.

\section{SYSTEMIC ORTHOPEDIC APPROACH}

The treatment of the human being as an unit and health with a harmonious multileveled integrated state, are not new concepts. Traditional healing systems have been practiced an holistic approach and preventive care millennia before modern times. By harvesting results derived from descriptive science (the so called ,reductionist” approach) medicine has come to the point of being able to regain integrality by means of advanced technology. For orthopedic science, however, what is considered today a revolutionary systemic view, has never been left aside. Orthopedics is the science of readjusting musculoskeletal system structure and functionality. Due to the complex and diverse objects of interest, the systemic approach is a built in reality and not a semantic synchronicity with modern trends in thinking. Orthopedists are trained to perceive body integrity and functionality as a condition of succesful intervention. There are a multitude of examples of practice where systemic approach has never been neglected, despite the narrowing of field of interest of orthopedic surgeons, gait is known to be the attribute of correct alignment, normal structure and function of axial and lower limb skeleton, muscle balance and conditioning. Any impairment has to be considered and treated in this context for a good, sustainable, result. In the open reduction and internal fixation procedure, systemic diseases, temporary conditions (like osteoporosis or anemia, hypo-proteinemy ) or environment (overload, professional stress) have a predictable impact on bone fixation as well as on healing length and quality of recovery.

An impressive quantity of available information extracted from hypothesis based studies has enabled perception of multiple correlations between pathological processes, leading to a systemic approach.

$\mathrm{OA}$ is classically regarded as an articular cartilage progressive degradation of multifactorial origin. There is increasing evidence that joint degeneration is a systemic disturbance with metabolic [49] vascular [50] or immune origin [51]. There is evidence about a connection between $\mathrm{OA}$ and metabolic syndrome. Adipokines like leptin, adiponectin, visfatin or resistin with multiple roles in fat metabolism or inflammation, have been linked to OA pathogeny [52]. Published scientific results contribute to updating the knowledge of the molecular pathways involved in cartilage and bone changes in osteoarthritis (OA), and in the detection of an increasing number of potentially effective candidates for therapy [53]. We propose that the use of in silico studies and experimental validation of computational results will reveal a link between obesity and joint pathology. The systems approach has begun to deliver useful information to enable clinicians to deal with hitherto untreatable degenerative conditions. Systems analysis of genome-wide expression data from salivary gland tissues of patients and mice models with Sjögren's syndrome has unveiled overlapping disease-related gene modules and common pathways, highlighting genes that could be a major focus of rodent-based validation studies, aiming for developing therapeutic targets [54].

Using computation and mathematical modelling, systems medicine integrates a variety of biological and medical data at all relevant levels. Detailed information derived from genomic studies is continously expanding our knowledge of cellular mechanisms, both of the normal and diseased states. However, we propose that systems medicine is not only the mere translation of omics" technologies in medical research and practice. Systemic thinking has the potential to integrate multilevel information at any scale of human system functioning, thus enabling focused preventive and therapeutical choice, personalized delivery and efficient participation. Programmed interventions at the subcellular, cellular, hierachical, molecular or environmental levels can promote general health and well-being and not just in the treatment of a disease.

The techniques of molecular medicine, biomarkers, targeted drug discovery and systemic medicine all contribute to the field of orthopedic science and practice and will continue to do so into the future.

\section{ABBREVIATIONS}

\section{$\mathrm{ECM}=$ Extracellular matrix}

EMR = Electronic Medical Records, computerized medical record created in an organization that delivers care, such as a hospital or physician's office system that allows storage, retrieval and modification of information 
(demographic data, history of diseases, treatments, medical imagistics, laboratory investigation)

GWAS = Genomic Wide Association Study, an examination of many common genetic variants in different individuals to see if any variant is associated with a trait. GWAS typically focus on associations between single-nucleotide polymorphisms (SNPs) and traits like major diseases

MFG-IRAP $=$ Multigene Familiy retrovirus developed as carrier of Interleukin-1 Receptor Antagonist Protein

MMP = Matrix Metalloproteinases

\section{CONFLICT OF INTEREST}

The authors confirm that this article content has no conflict of interest.

\section{ACKNOWLEDGEMENTS}

Declared none.

\section{REFERENCES}

[1] Evans CH, Rosier RN. Molecular biology in orthopedics: the advent of molecular orthopedics. Bone Joint Surg Am 2005; 87 (11): 2550-64.

[2] Runge MS, Patterson C, McKusick VA, Ed. Principles of molecular medicine. $2^{\text {nd }}$ ed. New Jersey: Humana Press 2006; pp. 53-5.

[3] Crick F. Central dogma of molecular biology. Nature 1970; 227 (5258): 561-3.

[4] Venter C, and all (HGP Consortium members). The sequence of human genome. Science 2001; 291 (5507):1304-51.

[5] Tevak Z, Kondratovich M, Mansfield E. US FDA and personalized medicine: In vitro diagnostic regulatory perspective. Per Med 2010; 7 (5): 517-30.

[6] Mobasheri A. Osteoarthritis year 2012 in review: biomarkers. Osteoarthr Cartil 2012; 20(12): 1451-64.

[7] Zhang Y, Jordan JM. Epidemiology of osteoarthritis. Clin Geriatr Med 2010; 26(3): 355-69.

[8] Poole R. Osteoarthritis initiative, NIH White Paper: Biomarkers, the Osteoarthritis Initiative. Available at: http://www.oarsi.org/pdf s/White_Paper_R_Poole_2-3-2000.pdf [Accessed: 17 November 2012].

[9] OARSI. Osteoarthritis Research International initiative, OARSI biomarkers global initiative. Available at: http://www.oarsi.org/ind ex2.cfm?section=OARSI Initiatives\&content=Biomarkers [Accessed: 17 November 2012]

[10] van Spil WE, Jansen NW, Bijlsma JW, et al. Clusters within a wide spectrum of biochemical markers for osteoarthritis: data from CHECK, a large cohort of individuals with very early symptomatic osteoarthritis. Osteoarthr Cartil 2012; 20(7): 745-54.

[11] Garnero P, Conrozier T, Christgau S, Mathieu P, Delmas PD, Vignon E. Urinary type II collagen C-telopeptide levels are increased in patients with rapidly destructive hip osteoarthritis. Ann Rheum Dis 2003;62(10): 939-43.

[12] Jansen NW, Roosendaal G, Lundin B, et al. The combination of the biomarkers urinary C-terminal telopeptide of type II collagen, serum cartilage oligomeric matrix protein, and serum chondroitin sulfate 846 reflects cartilage damage in hemophilic arthropathy. Arthritis Rheum 2009; 60(1): 290-8.

[13] Cuellar JM, Scuderi GJ, Cuellar VG, Golish SR, Yeomans DC. Diagnostic utility of cytokine biomarkers in the evaluation of acute knee pain. J Bone Joint Surg Am 2009; 91(10): 2313-20.

[14] Curtis JR, van der Helm-van Mil AH, Knevel R, et al. Validation of a novel multi-biomarker test to assess rheumatoid arthritis disease activity. Arthritis Care Res (Hoboken) 2012; 64(12): 1794803.
[15] Sowers MF, Karvonen-Gutierrez CA, Yosef M, et al. Longitudinal changes of serum COMP and urinary CTX-II predict X-ray defined knee osteoarthritis severity and stiffness in women. Osteoarthr Cartil 2009;17(12): 1609-14.

[16] González-Álvaro I, Ortiz AM, Alvaro-Gracia JM, et al. Interleukin 15 levels in serum may predict a severe disease course in patients with early arthritis. PLoS ONE 2011; 6(12): e29492.

[17] Argraves WS, Tran H, Burgess WH, Dickerson K. Fibulin is an extracellular matrix and plasma glycoprotein with repeated domain structure. J Cell Biol 1990; 111(6 Pt 2): 3155-64.

[18] Wang Y, Li D, Xu N, et al. Follistatin-like protein 1: a serum biochemical marker reflecting the severity of joint damage in patients with osteoarthritis. Arthritis Res Ther 2011; 13: R193.

[19] Wang Q, Rozelle AL, Lepus CM, et al. Identification of a central role for complement in osteoarthritis. Nat Med 2011;17 (12): 16749.

[20] Hao D, Li M, Wu Z, Duan Y, Li D, Qiu G. Synovial fluid level of adiponectin correlated with levels of aggrecan degradation markers in osteoarthritis. Rheumatol Int 2011; 31 (11): 1433-7.

[21] Xu L, Zhu GB, Wang L, Wang DF, Jiang XR. Synovial fluid omentin-1 levels are inversely correlated with radiographic severity of knee osteoarthritis. J Investig Med 2012; 60(3): 583-6.

[22] Berry PA, Jones SW, Cicuttini FM, Wluka AE, Maciewicz RA. Temporal relationship between serum adipokines, biomarkers of bone and cartilage turnover, and cartilage volume loss in a population with clinical kneeosteoarthritis. Arthritis Rheum 2011; 63(3): 700-7.

[23] Andersen DC, Krummen L. Recombinant protein expression for therapeutic applications. Curr Opin Biotechnol 2002; 13(2): 11723.

[24] Urist MR, Strates BS. Bone morphogenetic protein. J Dent Res 1971; 50: 1392-406.

[25] Spalszki M, Gunzburg R, Recombinant human morphogenic protein-2; a novel alternative too bone graft?. Acta Orthop Belg 2005; 71: 133-48.

[26] Fleischmann R, Iqbal I. Risk: benefit profile of etanercept in patients with rheumatoid arthritis, ankylosing spondylitis or psoriatic arthritis. Drugs Aging 2007; 24(3): 239-54.

[27] Chames P, Van Regenmortel M, Weiss E, Baty E. Therapeutic antibodies: successes, limitations and hopes for the future. $\mathrm{Br} \mathrm{J}$ Pharmacol 2009; 157(2): 220-33.

[28] Winkeler A, Sena-Esteves M, Paulis LE, et al. Switching on the Lights for Gene Therapy. PLoS ONE 2007; 2(6): e528.

[29] Evans CH, Ghivizzani SC, Robbins PD. Orthopedic gene therapy in 2008. Mol Ther 2009; 17(2): 231-44.

[30] Bandara G, Mueller GM, Galea-Lauri J, et al. Intraarticular expression of biologically active interleukin 1-receptorantagonist protein by ex vivo gene transfer. Proc Natl Acad Sci USA 1993; 90(22): 10764-8.

[31] Frisbie DD, Ghivizzani SC, Robbins PD, Evans CH, McIlwraith $\mathrm{CW}$. Treatment of experimental equine osteoarthritis by in vivo delivery of the equine interleukin-1 receptor antagonist gene. Gene Ther 2002; 9: 12-20.

[32] Evans CH, Robbins PD, Ghivizzani SC, et al. Clinical trial to assess the safety, feasibility, and efficacy of transferring a potentially anti-arthritic cytokine gene to human joints with rheumatoid arthritis. Hum Gene Ther 1996; 7: 1261-80.

[33] Ha CW, Noh MJ, Choi KB, Lee KH. Initial phase I safety of retrovirally transduced human chondrocytes expressing transforming growth factor-beta-1 in degenerative arthritis patients. Cytotherapy 2012; 14(2): 247-56.

[34] Adachi N, Sato K, Usas A, et al. Muscle derived, cell based ex vivo gene therapy for treatment of full thickness articular cartilage defects. J Rheumatol 2002; 29(9): 1920-30.

[35] Kim SH, Kim S, Oligino TJ, Robbins PD. Effective treatment of established mouse collagen-induced arthritis by systemic administration of dendritic cells genetically modified to express FasL. Mol Ther 2002; 6: 584-90.

[36] Le Maitre CL, Hoyland JA, Freemont AJ. Interleukin-1 receptor antagonist delivered directly and by gene therapy inhibits matrix degradation in the intact degenerate human intervertebral disc: an in situ zymographic and gene therapy study. Arthritis Res Ther 2007; 9: R83.

[37] Moon SH, Nishida K, Gilbertson LG, et al. Biologic response of human intervertebral disc cells to gene therapy cocktail. Spine 2008; 33: 1850-5. 
[38] Available at: http://www.clinicaltrials.gov/ct2/results?term=intradis cal+AND+gene [Accessed on: 30 Nov 2012].

[39] Ulrich-Vinther M, Carmody EE, Goater JJ, S balle K, O'Keefe RJ, Schwarz EM. Recombinant adeno-associated virus-mediated osteoprotegerin gene therapy inhibits wear debris-induced osteolysis. J Bone Joint Surg Am 2002: 84-A: 1405-12.

[40] de Poorter JJ, Tolboom TC, Rabelink MJ, et al. Towards gene therapy in prosthesis loosening: efficient killing of interface cells by gene-directed enzyme prodrug therapy with nitroreductase and the prodrug CB1954. J Gene Med 2005; 7: 1421-8.

[41] de Poorter JJ, Hoeben RC, Hogendoorn S, et al. Gene therapy and cement injection for restabilization of loosened hip prostheses. Hum Gene Ther 2009; 19: 83-95.

[42] Kostenuik PJ, Bolon B, Morony S, et al. Gene therapy with human recombinant osteoprotegerin reverses established osteopenia in ovariectomized mice. Bone 2004; 34(4): 656-62.

[43] Dass CR, Choong PF. Gene therapy for osteosarcoma: steps towards clinical studies J Pharm Pharmacol 2008; 60(4): 405-13.

[44] Available at: http://www.bbc.co.uk/news/health-20179561 [Accessed: 30 November 2012].

[45] Evans Ch, Givizzani SC, Robbins PD. Orthopedic gene therapy Lost in translation? J Cell Physiol 2012; 227: 416-20.

[46] Mashayekhi K, Labusca L. Systems biology meets systemic medicine: the old, the new and the blue. Proceedings of the Third International Conference on Emerging Security Technologies, EST, Lisabon, Portugal, 5-7 September IEEE CPS 2012; pp. 169-75.
[47] Auffray Ch, Chen Z, Hood L. Systems medicine; the future of genomics and healthcare. Genome Med 2009; 1(1): 2.

[48] DG Research. From systems biology to systems medicine. Bruselles: Report on European Commission. Directorate of Health Workshop, June 4-5, 2010; pp. 3-4.

[49] Aspen RM, Scheven BAA, Hutchinson JD. Osteoarthritis as a systemic disorder including stromall cel differentiation and lipid metabolism. Lancet 2001; 357: 1118-20.

[50] Conaghan PG, Vanharanta H, Dieppe PA. Is progressive osteoarthritis an atheromatous vascular disease?. Ann Rheum Dis 2005; 64: 1539-41.

[51] Potte P, Presle N, Terlain B, Netter P, Mainard D, Berembaum F. Obesity and osteoarthritis: more complex than predicted!. Ann Rheum Dis 2006; 65: 1403-5.

[52] Conde J, Scotece M, Gómez R, Lopez V, Gómez-Reino JJ, Gualillo O. Adipokines and osteoarthritis: novel molecules involved in the pathogenesis and progression of disease. Arthritis 2011; 2011: 203901 .

[53] Pulsatelli L, Addimanda O, Brusi V, Pavlovska B, Meliconi R. New findings in osteoarthritis pathogenesis: therapeutic implications. Ther Adv Chronic Dis 2013; 4(1): 23-43.

[54] Horvath S, Nazmul-Hossain, Pollard RP, et al. Systems analysis of primary Sjögren's syndrome pathogenesis in salivary glands identifies shared pathways in human and a mouse model. Arthritis Res Ther 2012; 14(6): R238.

(C) Mashayekhi et al.; Licensee Bentham Open.

This is an open access article licensed under the terms of the Creative Commons Attribution Non-Commercial License (http://creativecommons.org/licenses/by-nc/3.0/) which permits unrestricted, non-commercial use, distribution and reproduction in any medium, provided the work is properly cited. 